This is the author's final, peer-reviewed manuscript as accepted for publication. The publisher-formatted version may be available through the publisher's web site or your institution's library.

\title{
An application of dynamic thermal line rating control system to up-rate the ampacity of overhead transmission lines
}

S. D. Kim, and M. M. Morcos

\section{How to cite this manuscript}

If you make reference to this version of the manuscript, use the following information:

Kim, S. D., \& Morcos, M. M. (2013). An application of dynamic thermal line rating control system to up-rate the ampacity of overhead transmission lines. Retrieved from http://krex.ksu.edu

\section{Published Version Information}

Citation: Kim, S. D., \& Morcos, M. M. (2013). An application of dynamic thermal line rating control system to up-rate the ampacity of overhead transmission lines. IEEE Transactions on Power Delivery, 28(2), 1231-1232.

Copyright: (C) 2013 IEEE

Digital Object Identifier (DOI): doi:10.1109/TPWRD.2012.2234940

Publisher's Link: http://ieeexplore.ieee.org/xpl/articleDetails.jsp?arnumber=6407488

This item was retrieved from the K-State Research Exchange (K-REx), the institutional repository of Kansas State University. K-REx is available at http://krex.ksu.edu 


\title{
An Application of Dynamic Thermal Line Rating Control System to Up-rate the Ampacity of Overhead Transmission Lines
}

\author{
S. D. Kim, Member, IEEE, and M. M. Morcos, Senior Member, IEEE
}

\begin{abstract}
A method is proposed to utilize dynamic line rating (DLR) system on old transmission lines to up-rate ampacity without replacing old conductors or increasing line voltage. A DLR system applicable to double-circuit transmission lines is designed based on maximum allowable conductor temperature, conductor temperature at limit-dip (sag) margin, and transformer maximum load. The improved performance of the system is reported.
\end{abstract}

Index Terms-Ampacity, dynamic line rating, overhead lines.

\section{INTRODUCTION}

$\mathrm{T}$ Thermal rating of overhead transmission lines is selected based on standards associated with maximum allowable conductor temperature, conductor dip (sag), load capacity of transformers and protection relays. Line ratings are regulated by maximum temperatures allowable in power lines assuming that weather parameters are given under worst conditions. However, special weather conditions are actually applied in calculating specified ratings.

The key elements in the development of a dynamic line rating (DLR) system are the conductor type and temperature, ambient temperature, wind speed and its direction, in real time. Performance of DLR depends on conductor temperatures such as the maximum allowable temperature and limit-dip temperature [1-3]. As a result, transmission systems that apply DLR techniques can be treated as temperaturecontrol rather than current-control systems. The maximum allowable temperature of aluminum stranded conductor steel reinforced (ACSR) in Korea power lines is specified at $90{ }^{\circ} \mathrm{C}$; however, the design temperature is given as $40^{\circ}$ or $75{ }^{\circ} \mathrm{C}$, respectively, according to apply design standard for dip and ground clearance [4]. In this research, an improved method to apply DLR control system for existing old lines is introduced.

\section{AMPACITY OF TRANSMISSION LINE}

Transmission lines are generally designed by considering the dip that is determined based on design temperature and

S. D. Kim is with the Department of Electronic and Control Engineering, Hanbat National University, Daejeon, KOREA (e-mail: sdkim@hanbat.ac.kr).

M. M. Morcos is with the Department of Electrical and Computer Engineering, Kansas State University, Manhattan, KS, 66502, USA (e-mail: morcos@ksu.edu). maximum allowable temperature of the conductor. Most electric companies have their own standards for the upper limit of current or temperature, or conductor lifespan. These parameters are specified as suitable values to guarantee public safety and hold the reliability of power supply in service. Most power equipments are set a priori to any specific values of operating conditions. Hence, transmission systems can be regarded as deterministic control systems. DLR systems determine thermal rating dynamically, based on real-time conductor temperature (or current) in order for the conductor to reach maximum allowable temperature. Therefore, using DLR in real time can adjust power supply or load demand. Heating capacity of conductors depends on conductor type, conductor current, and weather factors [5]. Some of these variables may show time-varying characteristics. In general, DLR system can be a complex control system as it includes detecting, comparing, and calculating processes in real time; however, its control operation is very simple.

Static line rating (SLR) can be restricted by three main factors: a) specified allowable conductor current, b) specified ground clearance of conductor, and c) transformer capacity. Main transformer capacity in a substation is determined by using the nominal voltage of transmission line, load rate or line-utilization factor. Most transmission lines are designed in double-circuit connected in parallel in order to operate safely when one circuit is faulted. Under normal conditions each circuit can carry half of its full load. Therefore, transformer capacity should be designed so that the maximum allowable conductor temperature or current is not exceeded. A DLR system can be temperature-controlled where the load and weather factors - within expected ranges - are chosen as input parameters to the system.

In order to determine any specifications limiting the transmission conductor ampacity and guarantee safety of dip margin, it is necessary to use the maximum allowable temperature of conductor. Conductor dip - which depends on the tower design standards - is calculated using maximum conductor temperature and electric field strength. There are various transmission tower standards adopted by different electric companies, thus a unique solution for the dip margin cannot be obtained. For example, there are three types of overhead transmission lines in Korea which were built over three different periods using different standards for conductor dip [4]. 


\section{DynAmic Line RATING System DESIGN}

\section{A. System Structure}

In the case of a permanent fault in the line, the circuitbreaker disconnects the faulty line and its load is automatically added to the other circuit; hence no blackout should occur. The normal operating load of one circuit may be restricted below $50 \%$ of the maximum allowable load of transmission line. By way of an example, for a $154 \mathrm{kV}$ double-circuit transmission line (equipped with ACSR 410 bundle conductors) the maximum allowable load becomes 904 MVA per line. The design criterion of conductor temperature is specified at $40{ }^{\circ} \mathrm{C}$. The maximum total capacity of transformers is generally 240 MVA per substation.

\section{B. Dynamic Line Rating Control of Predicted Load}

The circuit consists of ACSR 410 bundle conductors with maximum allowable current of 1,696 A (since the SLR per conductor is $848 \mathrm{~A}$ ). Considering the predicted load of one circuit for 10 to 40 hours, the line is to deliver 750 A during normal operation, as shown in Fig. 1. When a sudden fault occurs on one line for 20 to 25 hours, it will break down and the non-faulty line has to carry a double load. To determine the DLR for the double-circuit transmission line, actual measured ambient temperature and wind speed are used. The maximum current limited by transformer capacity is designed to be $900 \mathrm{~A}$, corresponding to the total transformer capacity of 240 MVA. The healthy line can carry up to the maximum current of $1,800 \mathrm{~A}$. For analysis purposes, the design of a DLR system is only limited to the old lines with limit-dip conductor temperature of $51{ }^{\circ} \mathrm{C}[4]$.

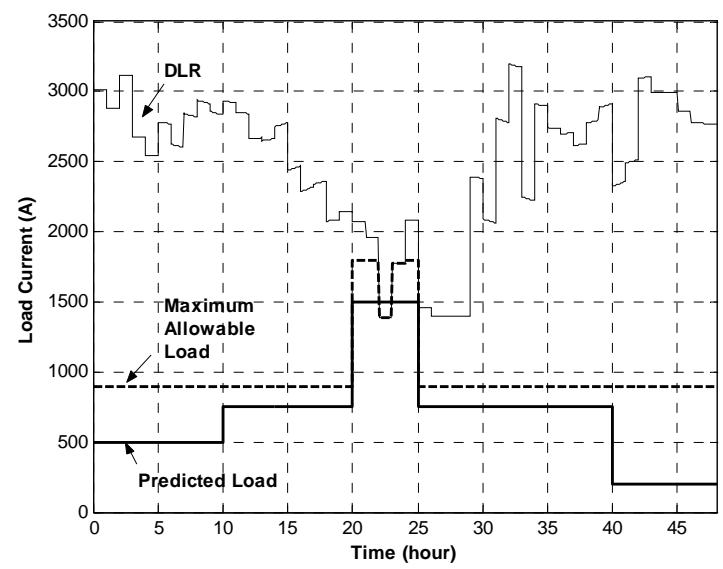

Fig. 1 Predicted load and dynamic line rating

For 0 to 20 and 25 to 48 hours of operation, the maximum allowable load is limited by transformer capacity. Between 20 and 25 hours, assuming a fault has taken place in one of circuits, the other circuit will carry a double load of 1,500 A. The line can carry maximum current of 1,696 A, and the conductor temperature should not exceed the maximum allowable limit. However, if the transmission line is designed for conductor temperature of $51{ }^{\circ} \mathrm{C}$ at limit-dip - for 22 to 23 hours of operation - the DLR and the predicted load become lower than the maximum allowable load. In this case, the load has to be restricted below DLR, thus avoiding the ground clearance to be below the standard levels.

\section{Case Study}

Performances of DLR and line loads for one of the double circuits are determined using actual load and weather data. The conductor temperature for designing ground clearance is set to the limit-dip temperature of $51{ }^{\circ} \mathrm{C}$. Fig. 2 shows a fault has occurred several times before 80 hours of operation have elapsed, and the load has been added - due to such fault - to the other healthy line. It can be seen that all maximum allowable loads are given as calculated DLR levels. As a result, the maximum allowable load can be further increased to about 135 \% for actual load, and to 52 \% for the SLR. Even when wind speed is assumed zero in calculating lower DLR, the maximum allowable load of $89 \%$ can be increased.

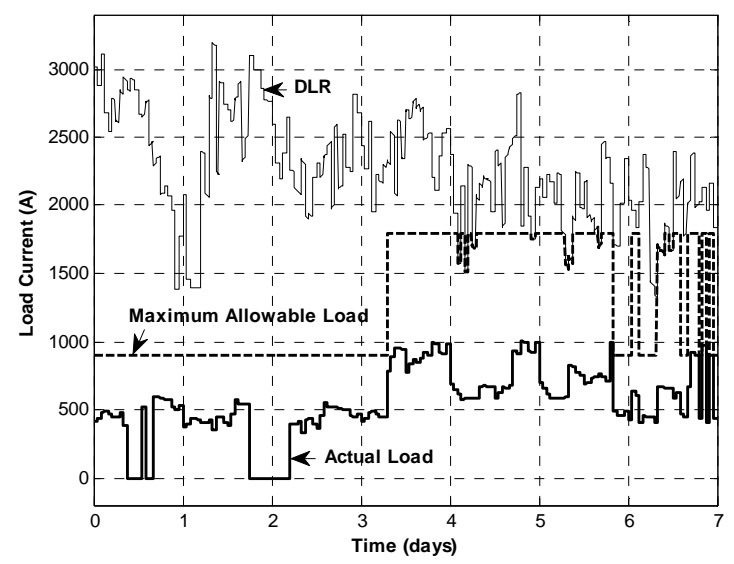

Fig. 2 Control performance of dynamic line rating system.

\section{CONCLUSIONS}

An improved method is proposed to utilize a DLR system for old transmission lines by applying older dip design standards. The maximum allowable conductor temperature, the conductor temperature at limit-dip, and the maximum capacity of main transformers have been applied in the computations. The DLR system applicable to actual transmission line is designed and analyzed based on real-time load and weather data measured on a sample transmission line. Several performances are presented in order to show the efficiency of DLR control systems.

\section{REFERENCES}

[1] D.A. Douglass and A.A. Edris, "Real-time monitoring and dynamic thermal rating of power transmission circuits," IEEE Trans. on Power Delivery, vol. 11, no. 3, pp. 1407-1418, 1996.

[2] A.K. Deb. Power-Line Ampacity System. CRC Press, 2000.

[3] L. Ren, J. Xiuchen and S. Gehao, "Research for dynamic increasing transmission capacity,” International Conference on Condition Monitoring and Diagnosis, Beijing, China, pp. 720-722, 2008.

[4] Design Standard for Dip of Overhead Transmission Lines, DS 1211, KEPCO, South Korea, 2004.

[5] IEEE Standard 738, IEEE Standard for Calculating the CurrentTemperature of Bare Overhead Conductors, 2006. 